\title{
Evaluation of the comfort of spontaneous respiration through three ventilator systems
}

\author{
M. K. Street and R. B. Hopkinson \\ Department of Anaesthesia, East Birmingham Hospital, Birmingham, UK \\ Received: 13 May 1986; accepted: 5 December 1986
}

\begin{abstract}
The use of intermittent mandatory ventilation and continuous positive airways pressure systems is widespread. The comfort of spontaneous ventilation through three systems, with a variety of humidifiers, has been evaluated. The use of demand flow systems and the introduction of some humidifiers caused considerable discomfort from fluctuations in the airway pressure. It is concluded that continuous flow systems are preferable and that fluctuations in airway pressure should not exceed $2.5 \mathrm{~cm} \mathrm{H}_{2} \mathrm{O}$.
\end{abstract}

Key words: Spontaneous breathing - Humidifiers Continuous flow - Demand flow - Equipment

The use of intermittent mandatory ventilation (IMV) or continuous positive airways pressure (CPAP) systems for the weaning of patients from mechanical ventilation is widespread. Clinical dissatisfaction has been expressed about the performance of ventilators currently in use in the United Kingdom [1].

Current systems provide either a continuous-flow or a demand-flow to the IMV or CPAP circuit. Gibney et al. [5] have demonstrated significant increases in the work of breathing through circuits using a demand valve.

Recent studies have shown that during CPAP the work of breathing is least when there is no change in airway pressure, as measured at the mouth, nor any time delay between the onset of inspiratory effort and the commencement of gas flow [3,4]. Similarly these requirements should apply to the spontaneous phase of IMV. An ideal system would be one in which the fluctuations in airway pressure are minimised.

Any ventilator can be used with a variety of humidifiers. These may impose an increase in respiratory work because of their own internal resistance
(Table 1). A humidifier may also decrease the ability of the ventilator to sense the respiratory effort of the patient whether flow or pressure triggered. The patient will then be required to provide increased effort to obtain inspiratory gas flow, or to open the expiratory valve.

An investigation has been conducted to quantify these effects on volunteers.

\section{Methods}

Three systems were studied in combination with three humidifiers, the Bennett Cascade, the Fisher-Paykel and the Engstrom Edith. Subjects were also tested breathing from atmosphere with tubing alone connected.

The systems investigated were the IMV option on the Siemens Servo B (Servo) and the Spontaneous option of the Engstrom Erica (Erica) ventilators, both of which use demand valves. They were compared with the continuous-flow Hudson IMV valve which can be adapted for use with many ventilators to provide IMV capability. In this investigation it was attached to a Brompton Manley ventilator in a manner similar to that previously described [6]. A fresh gas flow of $151 \mathrm{~min}^{-1}$ was provided to the IMV system but none to the ventilator.

All the equipment had been regularly serviced and fully checked before the study commenced.

Table 1. Resistance and compliance of humidifiers used in the study

\begin{tabular}{lll}
\hline & $\begin{array}{l}\text { Resistance } \\
\left(\mathrm{cmH}_{2} \mathrm{O} \text { at } 30 \mathrm{Imin}^{-1}\right)\end{array}$ & $\begin{array}{l}\text { Compliance } \\
\left(\mathrm{ml} \mathrm{cm} \mathrm{H}_{2} \mathrm{O}^{-1}\right)\end{array}$ \\
\hline Fisher-Paykel & 0.3 & 1.1 \\
Bennett Cascade & 3.5 & 1.5 \\
Edith & 0.5 & - \\
\hline
\end{tabular}




\section{Questionnaire}

Please ring correct answer

1. What time delay was there between the start of your inspiratory efforts and the commencement of gas flow?
A. None
B. Minimal
C. Moderate
D. Considerable
E. Excessive

2. What effort was required at the beginning of your inspiration to initiate gas flow?
A. None
B. Minimal
C. Moderate
D. Considerable
E. Excessive

3. What effort was required to maintain the gas flowing throughout the remainder of inspiration?
A. None
B. Minimal
C. Moderate
D. Considerable
E. Excessive

4. Was the quantity of gas supplied?
A. Insufficient
B. Less than adequate
C. Correct
D. More than adequate
E. Excessive

5. Did the supply of gas vary throughout inspiration?
A. Greater at the beginning
B. Not at all
C. Greater at the end

6. What time delay was there between your desire to exhale and the machine enabling you to do so?
A. None
B. Minimal
C. Moderate
C. Considerable
E. Excessive

7. What effort was required to stop the inspiratory gas flow and enable you to start to exhale?
A. None
B. Minimal
C. Moderate
C. Considerable
E. Excessive

8. What effort was required throughout expiration to enable you to exhale?
A. None
B. Minimal
C. Moderate
D. Considerable
E. Excessive

9. How did the circuit alter your respiratory pattern?
A. Respiratory rate
(a) Increased
(b) No change
(c) Decreased
B. Time taken for inspiration
(a) Increased
(b) No change
(c) Decreased
C. Time taken for
(a) Increased expiration
(b) No change
(c) Decreased

10. Did you have to think about each breath? Yes/no

11. Were you able to control the quantity of gas you wished to inhale?

12. What contributed to the comfort of breathing from the circuit?

A. Little effort required to obtain gas during inspiration

B. Little effort required to exhale

C. Quick response of the system to your respiratory cycle

D. Any other feature - please state: -

13. What contributed to the discomfort of breathing from the circuit?
A. Considerable effort required to obtain gas flow
B. Considerable effort required to exhale
C. Unable to control your respiratory pattern
C. Poor response of the system to your respiratory cycle
E. Any other feature - please state: -

Fig. 1. The subjective assessment of the performance of IMV ventilators when used in their spontaneous respiration phase in conscious volunteer subjects

The Fisher-Paykel and Bennett Cascade humidifiers were filled to their maximum point with water that was not heated. This prevented the subjects differentiating between systems on the basis of warmth or humidity and stopped excess condensation in the tubing which may have changed (adversely) the systems characteristics.

Each of the 14 fit volunteers, either nursing or medical staff wearing nose clips, breathed through a mouthpiece connected to one of 12 system/humidifier combinations hidden behind screens. This was performed in random sequence to minimise the effects of learning and adaptation.

One minute was allowed for the subjects to become accustomed to the system. The comfort of breathing was then assessed using a questionnaire to be completed while continuing to breathe from the system (Fig 1). This was designed with the aim of obtaining subjective assessments of the characteristics of each sytem, to complement objective measurements. Subjects judged the adequacy of gas supply and the time delays and effort entailed in both inspiration and expiration. Subjects were asked about perceived changes in respiratory pattern and features which contributed to the comfort or otherwise of breathing.

Measurements were made of changes in airway pressure at the mouth, and on the ventilator side of the humidifiers, using Hewlett-Packard pressure transducers (1290A). These and the simultaneous output from an infra-red carbon dioxide analyser (P.K.Morgan 


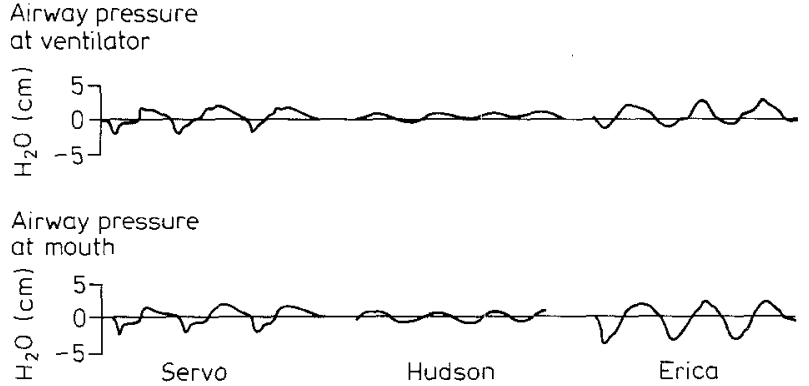

Fig. 2. Airway pressure traces from the three systems with the Cascade humidifier

$901 / 3045)$ were fed to a three channel chart recorder (Elcomatic EM740). Examples of these traces are shown in Figure 2.

Maximum and minium values for the pressure differences at the mouth $[\mathrm{dP}($ mouth $)]$ and ventilator [dP(vent)] were calculated as was the Inspiratory/Expiratory $(\mathrm{I} / \mathrm{E})$ ratio from the capnograph trace.

Wilcoxon matched pair rank sign tests were used for statistical analysis.

\section{Results}

\section{Subjective evaluation}

There was no subjective difference between breathing from atmosphere or from any of the systems using the Hudson IMV valve.
There was however a small increase in expiratory effort required which reached statistical significance for question 8 (Fig. 3).

For both ventilator based systems there were marked differences from breathing to atmosphere during both inspiration and expiration. A greater effort was required and longer time delays were experienced with all humidifiers attached to the Servo. During inspiration the differences from atmosphere were less marked when the Erica was used with the Edith or without a humidifier. In expiration the effort required and the time delays were even greater than those experienced with the Servo based system.

The volunteers observed that the proportion of their respiratory cycle taken for inspiration was extended when breathing from the Servo, in combination with any of the humidifiers, but not significantly when breathing from the machine alone.

The increase in respiratory effort was also responsible for the discomfort perceived particularly when the Servo was used with the Fisher-Paykel and Cascade humidifiers (Fig. 4).

Using the Erica based systems the volunteers felt that the time taken for expiration was prolonged. This caused considerable discomfort. Use of the FisherPaykel and Cascade humidifiers made the volunteers more conscious of each breath and the slow response of the ventilator increased the discomfort.

The quantity of gas provided by both ventilators was judged to be satisfactory unless used with the
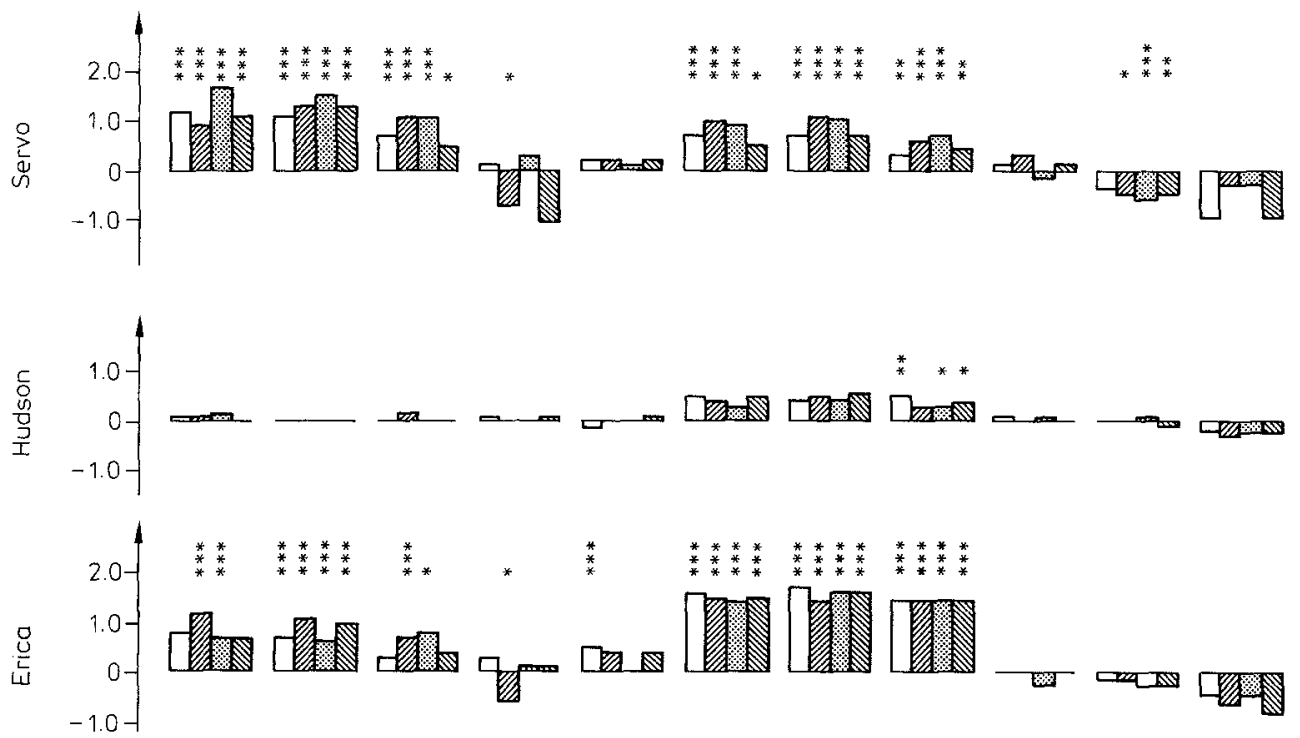

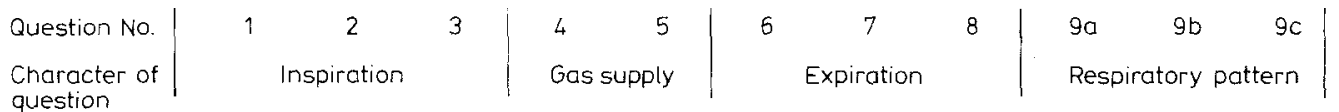

Fig. 3. Differences in answer rank between the IMV systems and atmosphere for questions $1-9 \mathrm{c} .{ }^{* * *} p 0.001,{ }^{* *} p 0.01,{ }^{*} p 0.5$. $\square$ no humidifier; Cascade; 圈 Fisher; Edith 

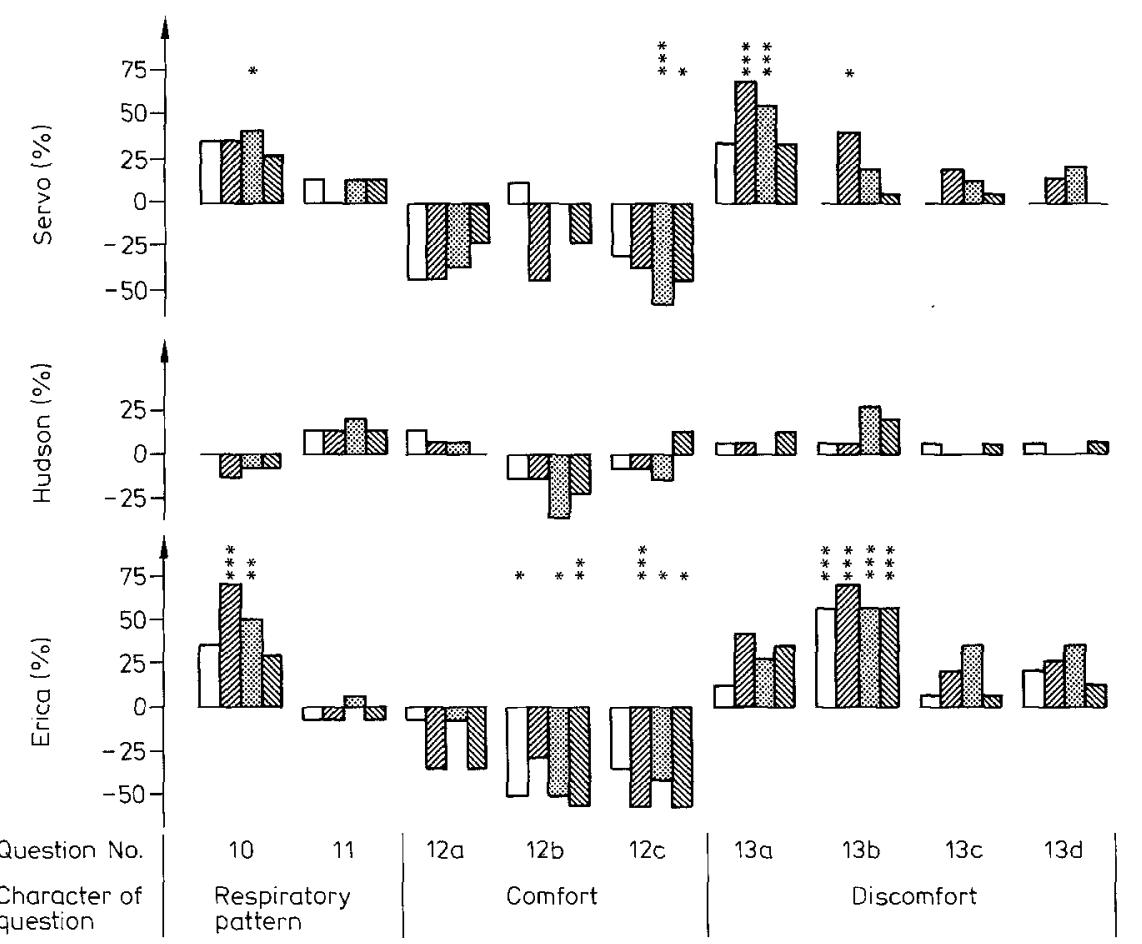

Fig. 4. Percent of volunteers with a positive change response between the IMV systems and atmosphere for questions $10-13 \mathrm{~d}$. *** $p 0.001$, ** $p 0.01,{ }^{*} p$ 0.5. $\square$ no humidifier; . Cascade; 鮝 Fisher Paykel; 图 Edith

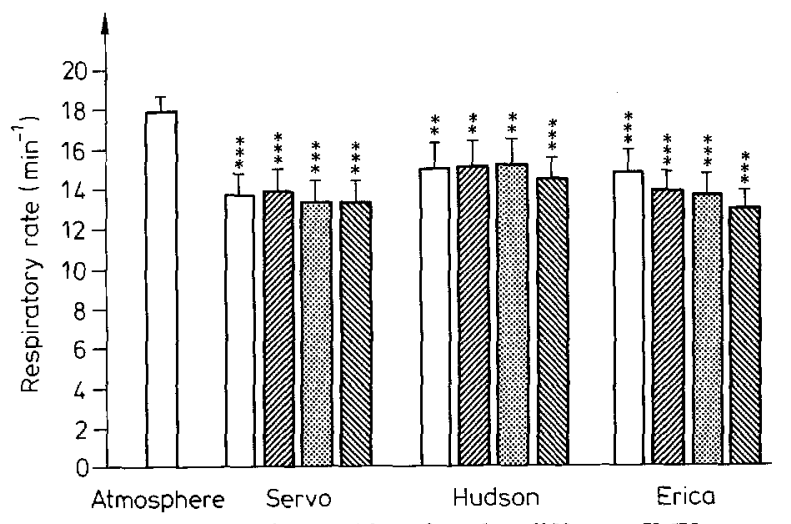

Fig. 5. Frequency of breathing for the different IMV systems. Significance of the difference from atmosphere ${ }^{* * *} p 0.001, * * p$ $0.01,{ }^{*} p$ 0.5. $\square$ no humidifier; Cascade; Fisher Paykel; $\mathbb{N}$ Edith

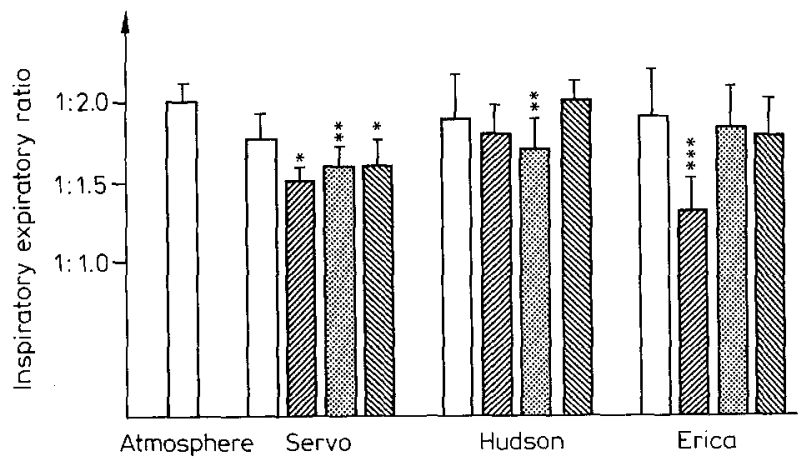

Fig. 6. Ratio of inspiratory to expiratory duration for the different IMV systems: $\square$ no humidifier; Cascade; Fisher paykel; Edith. Significance of the difference from atmosphere $* * * p 0.001$, $* *$ p $0.01, *$ p 0.5
Cascade humidifier. This reduced gas flow from both ventilators equally.

\section{Objective evaluation}

Significantly lower respiratory rates were recorded from the subjects breathing from any of the systems than when breathing from atmosphere. The fall in rate was least when the Hudson IMV valve was used, other than with the Edith humidifier (Fig. 5).

The I/E ratio was prolonged when the Cascade humidifier was used in conjunction with either the Servo but particularly the Erica ventilator (Fig. 6). A similar but less pronounced increase was found when the Servo system was used with the Edith or FisherPaykel humidifier, and the Hudson system with the Fisher-Paykel.

While there was no recordable pressure change at the mouth when breathing directly from atmosphere, when connected to any of the systems, significant positive and negative fluctuations in airway pressure were seen (Fig. 7). Using the Hudson valve $\mathrm{dP}$ was less than $2.5 \mathrm{~cm} \mathrm{H}_{2} \mathrm{O}$ for all the humidifiers. For the Servo the fluctuations were between 4.2 and $5.3 \mathrm{~cm} \mathrm{H}_{2} \mathrm{O}$ and for the Erica 5.3 and $6.5 \mathrm{~cm} \mathrm{H}_{2} \mathrm{O}$ (Fig. 2).

There was no statistical variation between the values obtained between different humidifiers using the same ventilator except when the Erica was used in combination with the Cascade humidifier. $\mathrm{dP}$ (mouth) was significantly greater $(p<0.01)$ with this humidifier 


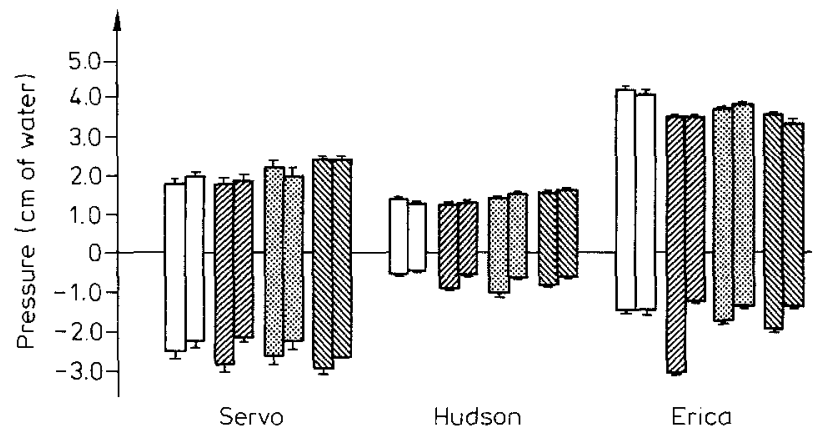

Fig. 7. Fluctuations in airway pressure both at the mouth (left-hand columns) and at the ventilator (right-hand columns) for the IMV systems: $\square$ no humidifier; $\mathbb{E}$ Cascade; 圈 Fisher Paykel; $\mathbb{N}$ Edith

than with the Edith, Fisher-Paykel or without humidifier. This was caused by the large negative pressure recorded $(p<0.01)$.

The pressure changes at the ventilator end of the circuit $\mathrm{dP}$ (vent) followed those at the mouth except when the Cascade humidifier was used with either the Servo or Erica. $\mathrm{dP}$ (vent) was significantly less than $\mathrm{dP}($ mouth $) \quad(p<0.01)$ for the Erica and Servo $(p 0.1>0.01)$. This was because the negative pressures recorded near the ventilator were less than those at the mouth, on the other side of the humidifier $(p<0.01)$.

\section{Comparison of Servo and Erica using the same humidifier}

The inspiratory time delay and effort required were subjectively greater with the Servo than with the Erica when used with the Fisher-Paykel humidifier (Table 2). Otherwise the two machines did not differ in their inspiratory characteristics.

The expiratory characteristics of the Erica were worse than those of the Servo. This was particularly so when the volunteers were breathing directly from the machines with no humidifier or when the Edith was used.

The maximum pressures recorded at the mouth and machine were higher with the Erica than the Servo (Table 3). Similarly, with the exception of the Cascade humidifier the minimum pressures were also higher resulting in no overall difference in $\mathrm{dP}$.

\section{Discussion}

There are a number of studies of the work of breathing through various ventilator systems using normal subjects or a mechanical lung $[1,5,7]$. All conclude that the ideal IMV circuit should not impose any additional work of breathing, any increased elastic threshold loads, upon the patient. There is no published work on the subjective impressions of breathing
Table 2. Statistical significances of the differences between the Erica and the Servo ventilators when breathing through the same humidifier. The changes are increases in rank order from the Servo unless indicated by $\downarrow$

\begin{tabular}{llllll}
\hline $\begin{array}{l}\text { Character of } \\
\text { question }\end{array}$ & $\begin{array}{l}\text { Question } \\
\text { no. }\end{array}$ & $\begin{array}{l}\text { No humi- } \\
\text { difier }\end{array}$ & Cascade & $\begin{array}{l}\text { Fisher } \\
\text { Paykel }\end{array}$ & Edith \\
\hline Inspiration & 1 & & $\downarrow 0.001$ & \\
& 2 & & $\downarrow 0.01$ & \\
Gas supply & 3 & 4 & & & \\
& 5 & & & 0.05 & \\
Expiration & 6 & 0.001 & & 0.01 \\
& 7 & 0.01 & & \\
Respiratory & 8 & 0.001 & 0.05 & & $\downarrow 0.05$ \\
pattern & $9 \mathrm{a}$ & & & \\
& $9 \mathrm{~b}$ & & & \\
& $9 \mathrm{c}$ & & & \\
& 10 & & & & \\
Comfort & 11 & & & & \\
& $12 \mathrm{a}$ & & & & \\
Discomfort & $12 \mathrm{~b}$ & $\downarrow 0.001$ & & & \\
& $12 \mathrm{c}$ & & & & \\
& $13 \mathrm{a}$ & & & & \\
& $13 \mathrm{~b}$ & 0.001 & & & \\
& $13 \mathrm{c}$ & & & & \\
& $13 \mathrm{~d}$ & & & & \\
\end{tabular}

through such systems. This questionnaire was designed to enable comparison of the subjects experiences with simply made objective recordings. Subjective assessment has been used before to assess qualitatively difficulties in breathing [8].

While the subjects could not distinguish the difference between breathing from atmosphere and through the Hudson IMV value there were measurable changes in respiratory rate and $\mathrm{dP}$.

Cox and Niblett [2] recommended that fluctuations in airway pressure of $5 \mathrm{~cm} \mathrm{H}_{2} \mathrm{O}$ should be acceptable to patients and yet in this study subjects were clearly able to distinguish between atmosphere and

Table 3. Statistical significances of the differences of the objective results between the Erica and the Servo ventilator when breathing through the same humidifier

\begin{tabular}{|c|c|c|c|c|}
\hline & $\begin{array}{l}\text { No humi- } \\
\text { difier }\end{array}$ & Cascade & $\begin{array}{l}\text { Fisher } \\
\text { Paykel }\end{array}$ & Edith \\
\hline \multicolumn{5}{|c|}{ Respiratory rate } \\
\hline \multicolumn{5}{|l|}{ I: E Ratio } \\
\hline \multicolumn{5}{|c|}{ Pressure at mouth } \\
\hline maximum & 0.001 & 0.001 & 0.001 & \\
\hline miminum & 0.001 & & 0.001 & 0.5 \\
\hline $\mathrm{dp}$ & & 0.001 & & \\
\hline \multicolumn{5}{|c|}{ Pressure at ventilator } \\
\hline maximum & 0.01 & 0.001 & 0.001 & \\
\hline minimum & 0.01 & & 0.001 & 0.001 \\
\hline $\mathrm{dp}$ & & 0.001 & & \\
\hline
\end{tabular}


IMV systems were $\mathrm{dP}$ exceeded $2.5 \mathrm{~cm} \mathrm{H}_{2} \mathrm{O}$. It would therefore appear that pressure swings, either positive or negative, of greater than $2.5 \mathrm{~cm} \mathrm{H}_{2} \mathrm{O}$ are unacceptable in ventilator systems where the patients are breathing spontaneously.

Inspiratory flow is initiated in the Servo by a fall in airway pressure and in the Erica by production of a gas flow of $100 \mathrm{ml} \cdot \mathrm{s}^{-1}$. The Servo used was set on its minimum inspiratory threshold of $2 \mathrm{~cm} \mathrm{H}_{2} \mathrm{O}$. No gas would have flowed until the machine sensed this fall in pressure. This caused the characteristic downward " $\mathrm{v}$ " on the recording of airway pressure at the mouth (Fig. 2). The need to generate this pressure will account for the poor subjective performance of the ventilator during inspiration and have resulted in an increased work of breathing. Christopher et al. [1] conclude that it may be necessary for such patients to develop 50 percent of their initial maximal inspiratory force (NIF) to initiate a tidal breath and that this could result in failure to wean from the ventilator.

Subjective and objective results demonstrated that with the Erica system gas flow was easier to initiate than with the Servo, but gas flow once established required considerable effort to terminate. This difficulty in opening the expiratory valve caused considerable discomfort to the subjects and would further increase work of breathing.

For both the Servo and the Erica the sensor, of pressure or flow, is housed in the body of the ventilator providing a long conduction pathway. Humidification systems, designed primarly for Controlled Mechanical Ventilation, are placed in the inspiratory limb and will modify the changes in flow or pressure detected by the ventilator as they provide variable resistive and capacitative loads (Table 1).

The results indicated that the use of the FisherPaykel and Cascade humidifiers increased the time delay between initiation and commencement of gas flow. In particular the Cascade humidifier, when used in conjunction with the Erica with which it was sold, demonstrated a dramatic objective increase in the peak negative pressure required. Unlike the Servo this was sustained throughout inspiration. The combination of Erica and Cascade result in a considerable increase in the respiratory effort and cannot be recom- mended for use as a circuit for spontaneous respiration. Further studies on the use of the "inspiratory assist" mode are required.

The choice of humidifier for use with the Hudson IMV system is not critical.

Subjective assessment has demonstrated that continuous flow IMV systems are most similar to breathing from atmosphere. If demand flow ventilators are used, particular care is needed in the choice of humidifier. Fluctuations in airway pressure during quiet respiration should be less than $2.5 \mathrm{~cm} \mathrm{H}_{2} \mathrm{O}$ in order to minimise the additional respiratory work imposed by the IMV system.

In patients experiencing respiratory difficulty the use of some systems may hinder or prevent weaning from ventilation and cause considerable discomfort in the process.

\section{References}

1. Christopher KL, Neff TA, Bowman JL, et al. (1985) Demand and continuous flow intermittent mandatory ventilation systems. Chest 87:635

2. Cox D, Niblett DJ (1984) Studies on continuous positive airway pressure breathing systems. Br J Anaesth 56:905

3. Douglas ME, Downs B (1978) Cardiopulmonary effect of PEEP and CPAP. Anesth Analg 57:347

4. Gherini S, Peters RM, Virgilio RW (1979) Mechanical work on the lungs and work of breathing with positive end expiratory pressure and continuous positive airway pressure. Chest 76:251

5. Gibney RTN, Wilson RS, Pontoppidan H (1982) Comparsion of work of breathing on high gas flow and demand valve continuous positive airway pressure systems. Chest 82:692

6. Lawler PGP, Nunn JF (1977) Intermittent mandatory ventilation. Anaesthesia 32:138

7. Marini JJ, Capps JS, Culver BH (1985) The inspiratory work of breathing during assisted mechanical ventilation. Chest 87:612

8. Stark RD, Gambles SA, Lewis JA (1981) Methods to assess breathlessness in healthy subjects: a critical evaluation and application to analyse the acute effects of diazepam and promethazine on breathlessness induced by exercise or by exposure to raised levels of carbon dioxide. Clin Sci 61:429

\footnotetext{
Dr. Rowland B. Hopkinson

Intensive Therapy Unit

Department of Anaesthesia

East Birmingham Hospital

Birmingham B9 5ST

UK
} 